\title{
Contemporary Approaches to Diagnostics and Treatment of Foramen Magnum Meningiomas
}

\author{
Shanko Yuri ${ }^{1}$, Smeyanovich Arnold ${ }^{1}$, Tanin Andrei ${ }^{1}$, Sych Ekaterina ${ }^{1}$, Smeyanovich Vitali ${ }^{1}$, Bulgak \\ Uladzimir ${ }^{1}$, Hubkin Siarhei ${ }^{2}$, Zamaro Alexandra ${ }^{2}$, Navitskaya Valeria ${ }^{1}$ and Kulchitsky Vladimir*2
}

${ }^{1}$ Republican Research and Clinical Center of Neurology and Neurosurgery, Republic of Belarus

${ }^{2}$ Brain Center, Institute of Physiology, National Academy of Sciences, Belarus

*Corresponding author: Kulchitsky Vladimir, Brain Center, Institute of Physiology, National Academy of Sciences, Minsk, Belarus

\section{ARTICLE INFO}

Received: 蔧 May 07, 2019

Published: 幽 May 13, 2019

Citation: Shanko Y, Smeyanovich A, Tanin A, Sych E, Smeyanovich V, Bulgak U, Hubkin S, Zamaro A, Navitskaya V, Kulchitsky V. Contemporary Approaches to Diagnostics and Treatment of Foramen Magnum Meningiomas. Biomed J Sci \& Tech Res 18(1)-2019. BJSTR. MS.ID.003081.

Keywords: Craniocervical Junction Area; Foramen (Occipitalis) Magnum; Meningiomas; Microsurgery; Stem Cells, Surgical Outcomes

\author{
ABSTRACT
}

34 cases of cranio cervical junction area meningiomas were analyzed. These can be found among $1.6 \%$ of the total number of patients with primary symptomatic intracranial meningiomas. Lateral or anterolateral tumor localization was observed in $31(91.2 \%)$ cases, posterior - in 2 (5.9\%), anterior without lateralization - in 1 (2.9\%). 27 (79.4\%) patients underwent surgical intervention within suboccipital approach, 7 (20.6\%) - posterolateral suboccipital (transcondylar) approach. Total tumor resection was performed in 24 $(70.6 \%)$ cases, subtotal - in $6(17.6 \%)$ cases, partial - in 4 (11.8\%). Postoperative mortality and tumor recurrence were not observed during the whole observation period. Suboccipital lateral approach with laminectomy to the level of lower tumor pole was enough to provide adequate microsurgical craniovertebral meningioma resection without resection of atlanto-occipital articulation. The approach to neoplasm matrix was performed after tumor partial resection without brain stem traction. The use of intraoperative neuromonitoring provided control of brain stem functions at all stages of tumor resection and vertebral artery isolation.

Abbreviations: IX, X, XI: Cranial Nerves Designations; C2: Vertebra Designations; CT: Computed tomography; FM: Foramen Magnum; MRI: Magnetic Resonance Imaging; WHO: World Health Organization

\section{Introduction}

There has been a significant change in the structure of intracranial tumors this past decade. According to CBTRUS, in 1994, gliomas totaled $46.5 \%$ (including glioblastomas - 23.3\%) of all brain neoplasms, meningiomas - $24.8 \%$, other tumors $-28.7 \%$, in 2007-2011 the share of gliomas decreased to $27.8 \%$ (including glioblastomas - 15.6\%), but the meningiomas percentage increased up to $35.8 \%$ and other tumors to $36.4 \%[1,2]$. Intracranial meningiomas, in the overwhelming majority, belong to the benign neoplasms (WHO Grade I-II) [3-5] with slow growth and progredient progression. A separate group consists of skull base meningiomas characterized by complex anatomical interrelations and high sensitivity of surrounding structures to surgical manipulations. The neoplasm removal is associated with solving the function preservation problem of intracranial neural and vascular structures, which is ensured using wide possibilities of microneurosurgery: surgical optics, neurophysiological monitoring, etc. [6]. Due to specific symptoms, complicated surgical anatomy and unique operating conditions, a special group of meningiomas is distinguished - meningiomas of the craniocervical junction or the Foramen Magnum (FM).

These neoplasms represent, by various estimates, around $0.3 \%$ to $1.8-3.2 \%$ of all intracranial meningiomas (1 case per 2-7 million people per year) [6,7]. It is believed that among all meningiomas, FM localization has the worst results in terms of postoperative mortality and surgical complications. The rarity of clinical observations, complex anatomical localization and high surgical risks suggest individual treatment planning. Anatomically, the region of Foramen Magnum is considered in the following borders: 
anterior - from the lower third of the clivus to the upper edge of $\mathrm{C} 2$ vertebra body; lateral - from the jugular tubercle of the occipital bone to the upper edge of $\mathrm{C} 2$ vertebra arc; posterior - from the anterior margin of the occipital bone scales to $\mathrm{C} 2$ vertebra spinous process [8-13].

\section{Materials and Methods}

This study includes 34 observations; patients aged 18 to 75 years (median age 52.8 years) in the period from 1991 to 2016 There were 7 men, 27 women (ratio M: F -1:3.9). This amounted to about $1.6 \%$ of the total patient number with symptomatic meningiomas. It is believed that only $25 \%$ of meningiomas are symptomatic [9], and the rest are identified as incidental findings in routine examinations or autopsy. In our study, all tumors were symptomatic; there was not a single incidental detection of FM Meningioma on Magnetic resonance imaging (MRI) or CT. The duration of manifestation prior to diagnosis was 2.5 to 48 months (median duration 14.8 months). Clinical symptoms are presented in Table 1.

Table 1: Neurological symptoms of FM meningiomas.

\begin{tabular}{|c|c|}
\hline Clinical symptom & Frequency of observations \\
\hline $\begin{array}{l}\text { Headache with cervico-occipital } \\
\text { localization }\end{array}$ & $34(100 \%)$ \\
\hline Vertigo & $22(64.7 \%)$ \\
\hline Pyramidal insufficiency & $34(100 \%)$ \\
\hline Motion coordination disorders & $18(52.9 \%)$ \\
\hline $\begin{array}{c}\text { Neuropathy of the cranial nerves } \\
\qquad \text { IX, X, XI } \\
\text { XII }\end{array}$ & $\begin{array}{c}19(55.9 \%) \\
6(17.6 \%)\end{array}$ \\
\hline Neuropathy of roots $\mathrm{C} 1-\mathrm{C} 2$ & $22(64.7 \%)$ \\
\hline $\begin{array}{l}\text { Atrophy of sternocleidomastoid and } \\
\text { trapezius muscles }\end{array}$ & $11(32.4 \%)$ \\
\hline Edema of the optic disc & $18(52.9 \%)$ \\
\hline Occlusal crises & $7(20.6 \%)$ \\
\hline
\end{tabular}

The most frequent disease manifestation symptom was pain in cervico-occipital area, which was enhanced by head flexion - was observed in all 34 (100\%) patients. All of them were registered progressive pain in this specific location with growth to paresthesias in hands. These symptoms were the main and most distinct in the clinical manifestation of FM meningiomas. Pyramidal insufficiency of varying severity degree was also noted in all 34 (100\%) patients. However, in 1 (2.9\%) case the patient could not move independently for about 3 months because of tetraparesis, and in 4 (11.8\%) observations there were significant motor functions limitations. Most of the examined patients had pyramidal disorders with moderate expression. 22 (64.7\%) patients demonstrated vertigo. Somewhat less often, there were coordination disorders - 18 (52.9\%) patients. Very frequent symptoms were the neuropathies of cranial nerves: IX, X, XI - in 19 (55.9\%) patients, XII - in 6 (17.6\%). Due to the accessory nerve lesion, the atrophy of trapezius and sternocleidomastoid muscles developed in 11 (32.4\%) observations. 22 (64.7\%) patients were registered thermal dysesthesia, astereognosis and anesthesia in C1-C2 dermatomes.

As a rule, patients made account of pain in the cervico-occipital location, motor disorders and ataxia. Occlusive crises were registered in 7 (20.6\%) patients. Optic disc edema was detected in $18(52.9 \%)$ examined patients. All patients, in the study and control groups, underwent a comprehensive examination according to neurooncological standards. The basis for FM meningioma diagnosis was CT and MRI integrated use. The main tasks of neuroimaging are the following: tumor localization in FM, rectification of its relationship with the brain stem (lateralization) and vertebral arteries, determination of extradural expansion. Meningiomas of small and medium sizes (up to $1 / 2$ of FM diameter, less than $2.5 \mathrm{~cm}$ in the largest measurement) were observed in 8 (23.5\%) patients, and large meningiomas (more than $1 / 2$ of FM diameter, more than $2.5 \mathrm{~cm}$ in the largest measurement) - in 26 (76.5\%). The lateral and anterolateral tumor location was observed in 31 cases (91.2\%), posterior - in 2 (5.9\%), anterior without lateralization - in 1 (2.9\%) (Figure 1).

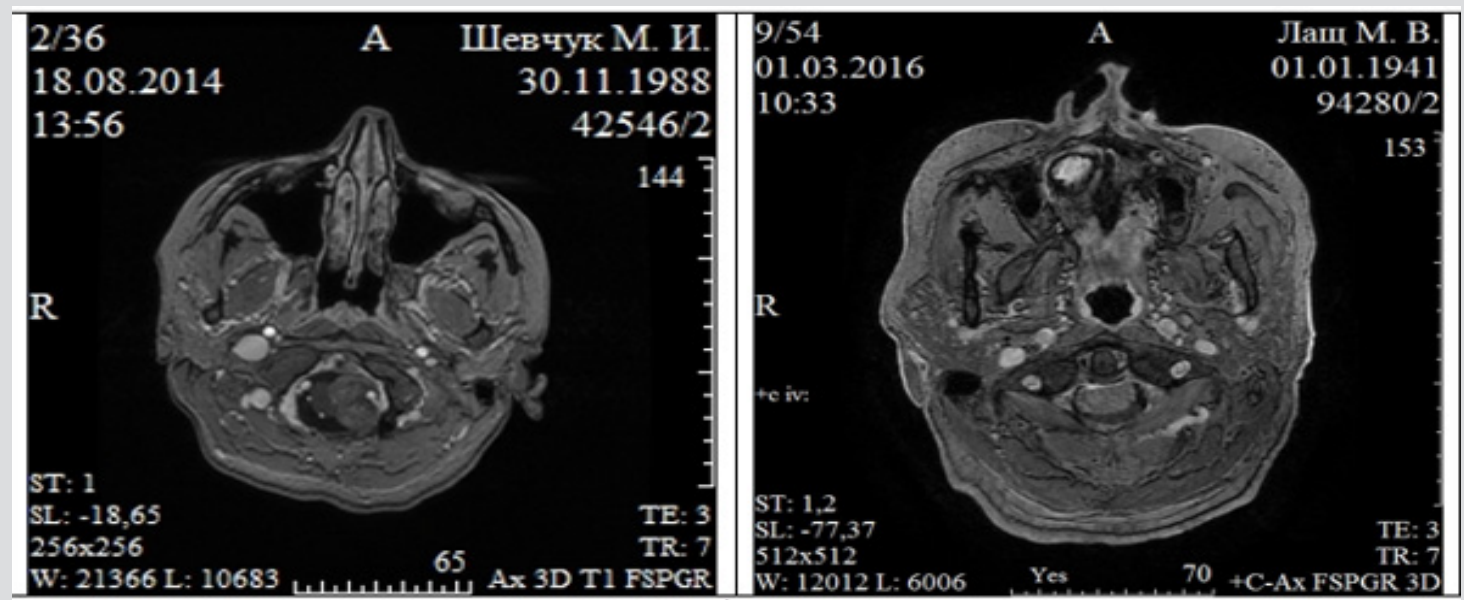

Figure 1: Foramen magnum meningiomas of ventral localization (arrows) with (left) and without lateralization (right). 
FM meningiomas at CT are determined as neoplasms of round or oval form of iso- or slightly hyperintensive density. Hypodensive meningiomas were not identified. The accumulation of contrast in all cases was mostly homogeneous. Intra-tumor cysts were not detected in any observation in FM meningiomas. Small size calcinates were detected only in $2(5.9 \%)$ cases. IV ventricle was compressed and displaced or enlarged with caudal arrangement of the tumor. Hydrocephalic dilatation of lateral and third ventricles was noted in $25(73.5 \%)$ observations. The wide tumor base adjacent to the dura mater was an indispensable feature of FM meningiomas. An invasive growth into the bone tissue was observed in $4(11.8 \%)$ cases. Bone changes (hyperostosis) caused by FM meningiomas did not have a significant size in our study. These neoplasms were not characterized by perifocal changes, which are not very typical for meningiomas. The frequency of such changes caused by meningiomas with different localizations is $50-83 \%$ [6]. The possibilities of dual-energy SCT method allowed to not only provide 3D bone reconstruction with the tumor node projection on them, but also SCT - angiography with the projection of the main vessels onto the tumoral nodes (Figure 2).

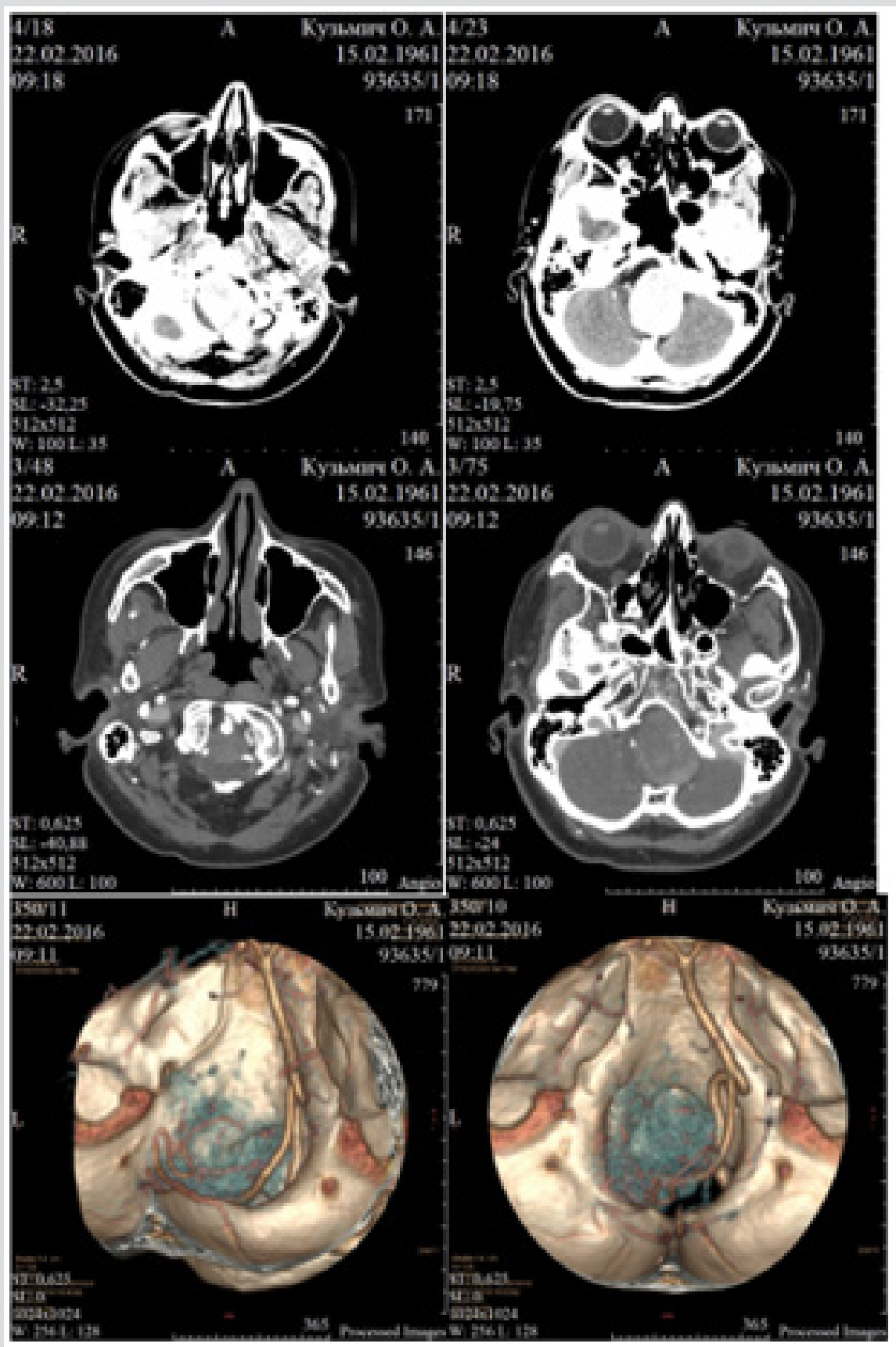

Figure 2: Dual-energy spiral computed tomography of patient K., 55 y.o. Foramen magnum meningioma of anterolateral localization (left). Spiral computed tomography with intravenous contrast enhancement (up).

CT angiography (middle). 3D reconstruction: tumor is painted blue, vertebral and basilar arteries dislocated by tumor to the right (bottom). 
The internal structure heterogeneity of meningiomas and the wide variety of their MRI variants are determined by the histobiological tumor properties. No specific MRI patterns were traced by us in FM meningiomas. Practically all meningiomas were characterized by a pronounced homogeneous accumulation of paramagnetic intravenous contrast agent. Local perifocal changes around FM meningiomas were detected only in 5 (14.7\%) patients, generalized perifocal changes - not detected in any case. One of the most significant FM meningiomas MRI signs is the cerebral fluid fissure between the tumor node surface and brain structures with blood vessels in it [6]. In FM meningiomas, unlike other meningiomas localizations, this specific sign was not detected in all cases. Full or partial obturation is caused by the arachnoid sheath adhesions with the underlying superficial parts of the brain, which are caused by proliferative changes developed at the tumor edge.

Complete preservation of the peritumorous cerebral fluid fissure was noted in $4(11.8 \%)$ patients, partial obturation in 22 (64.7\%), complete obturation in 8 (23.5\%) (complete obturation is rarely observed with supratentorial meningiomas). Dura mater invasion was detected without contrast enhancement due to thickening of the latter and the outer contour deformation $[6,7]$. The use of contrast enhancement increased the abilities to diagnose dura mater neoplasm invasion. This symptom was noted in 7 (20.6\%) patients. According to MRI data, tumor growth all around vertebral artery was detected in 12 (35.3\%) cases (Figure 3). But this is not completely correct data, intraoperatively the dura mater invasion around the vertebral artery was observed in 18 (52.9\%) observations.

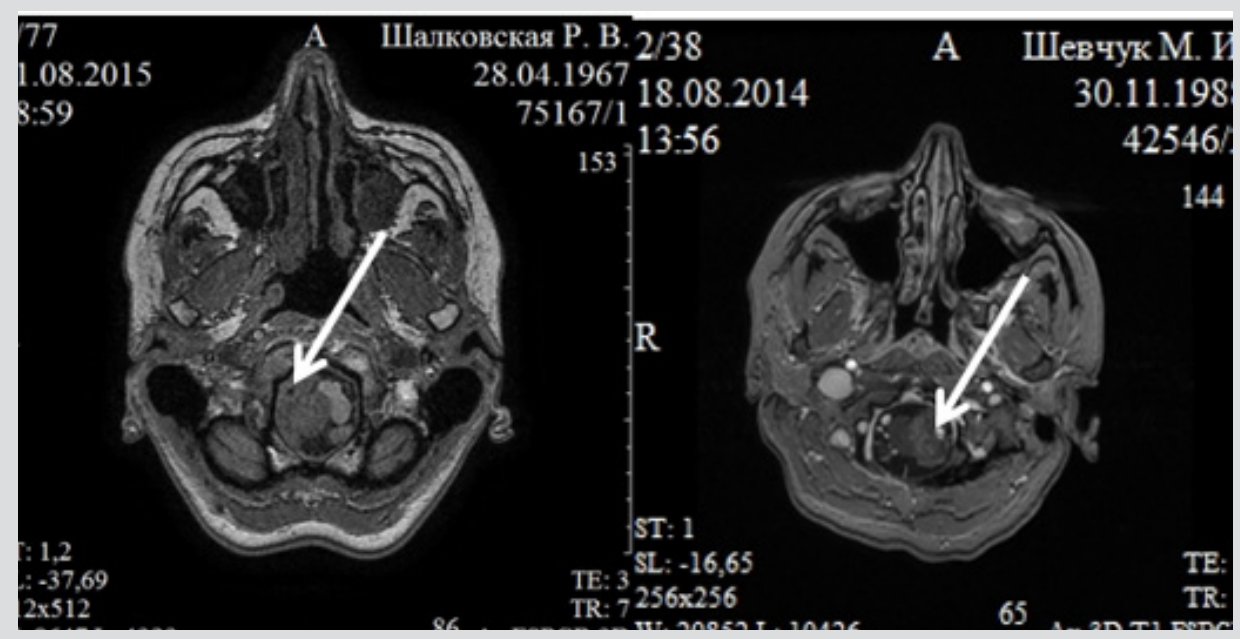

Figure 3: Tumor grows around vertebral artery (MRI data) (basilar artery is marked with arrows).

We used the midline posterior (suboccipital) in 27 (79.4\%) and posterolateral transcondylar 7 (20.6\%) surgical approaches with lateralization. The midline posterior approach is considered optimal for posterior meningiomas - in these cases the brain structures are shifted anteriorly from the tumor. Posterolateral (far lateral or lateral) approach was first proposed by Koos WTH et al. [13], and Babu RP et al. [14], and modified by Heros RC [15] and Perneczk A [16]. It provides a lower-lateral approach, if necessary - double-sided, to the ventral surface of the brainstem without brain retraction. The described variants differ only in the condyles resection degree and mobilization of the vertebral artery. After the VA mobilization, it was displaced downwards, and the resection of the occipital condyle posterior part was performed with the drill. We avoided the junction resection more than 50\% to avoid craniocervical instability. It is believed that partial condylectomy can significantly expand the surgical corridor.

The performed incisions of dura mater were Y-shaped or horseshoe-shaped, retracted with stitches. According to matrix accessibility, tumor resection was started with the devascularization of its posteroinferior portion. Then meningioma was enucleated in parts and separated from the rootlets of the spinal cord and lower cranial nerves. The medial and anterior tumor parts were removed last, after complete devascularization took place, in a dry operative field, with a minimal brainstem displacement. If the matrix was inaccessible, the removal was started with tumor enucleation using ultrasonic aspirator within visible limits with thorough gradual hemostasis. The enucleation area was expanded toward the matrix, which was coagulated, starting with its middle part. Gradually, the posterior tumor portion was devascularized and removed, releasing lower cranial nerves, cervical rootlets. Thus, surgical corridor was expanded significantly, which provided well-controlled manipulations on the remaining medial tumor portion and its matrix. After resection of the latter and cutting it off from dura mater the medial portion of the tumor was gradually dislocated and removed in parts. In 3 (11.3\%) cases, the control of manipulations was provided by using an assisting endoscopy.

According to the dural insertion with the tumorous tissue, a partial or complete resection of its affected areas (anterior or posterior to the vertebral artery) was performed - 7 (20.6\%) cases. Vertebral arteries mobilization from the tumor mass is 
associated with a risk of ischemia; therefore, it required thorough intraoperative neurophysiological monitoring. We succeeded in VAs mobilizing and dissecting them from the tumor all the way from the site of its penetration through the dura mater in 14 (41.2\%) patients. In $4(11.8 \%)$ cases, the VA mobilization and tumor resection were limited by neuromonitoring indications (a sharp decrease of somatosensory evoked potentials amplitude) or anesthesiological limitations (persistent bradycardia and blood pressure decrease). Muscle patch was used to close dura mater. Muscular and aponeurosis layers were tightly closed.

\section{Results}

To assess the extent of surgical treatment, we used the gradation system Simpson [17]. Total removal of FM meningiomas (Simpson 2) was performed in 24 (70.6\%) cases, subtotal (Simpson 3 ) - in 6 (17.6\%), partial (Simpson 4) - in 4 (11.8\%). There was no postoperative mortality. Tumor resection was performed in two stages, in one case, because of decrease in blood pressure to $60 \mathrm{~mm} \mathrm{Hg}$ and bradycardia during the first intervention, probably due to brainstem dislocation. The remaining tumor portion was completely removed after 5 months. In the early postoperative period, lower cranial nerves and C1-C2 rootlets dysfunctions were registered in 19 (55.9\%) patients, and 13 (38.2\%) had mild or moderate pyramidal disorders. Cerebellar ataxia was noted in 22 (64.7\%) observations. Clinically significant pneumocephaly was noted in $3(8.8 \%)$ cases, which required air extraction (patients were operated in the sitting position).

There were no hemorrhagic complications in any case. Postoperative radiosurgery (gamma-knife) was carried out in 1 (2.9\%) case (after subtotal tumor removal), radiotherapy - in 4 $(11.8 \%)$ cases after partial and subtotal FM meningioma resection. Functional outcomes were initially estimated according to the Karnofsky Performance Scale in the period from 6 to 14 months after the surgery. 90-100\% (no disability or vital activity) - 23 (67.7\%) patients, $70-80 \%$ (mild disability and vital dysfunction) $8(23.5 \%)$ patients, $50-60 \%$ (moderate disability and life-support needs) - 3 (8.8\%) patients whose tumor was partially removed. There were no gross neurological disorders, which significantly restricted the ability to work and live. All patients were or continued to be monitored, according to clinical protocols. They were recommended to undergo a control MRI at least once a year. Catamnesis was up to 19 years. There were no repeated complaints about recurrence or continued FM meningioma growth in either case, even after subtotal or partial tumor removal.

Bulbar disorders and deep right-sided hemiparesis were observed in postoperative period in a single patient after separation of tumor from brain stem and vertebral artery (total tumor resection). Autologous MSCs from adipose tissue (6.0$8.0 \times 10^{\wedge} 6$ cells) were used in complex postoperative treatment (submucous perineural implantation [18-21]). Migration of MSCs led to distinct progressive recovery of functions: bulbar disorders completely regressed in four months, hemiparesis disappeared, and motor coordination recovered. Patient wears heels and likes dancing 4 months later. Information on the ability of stem cells to differentiate in a neuron-like direction after microglia activation is the fundamental basis for this tactic [22]. There are experimental data [23] confirming that implanted stem cells form synaptic contacts with endogenous brain neurons close to neurodestruction area after differentiation into neuron-like elements. By the way, it is paradoxical, but stem cells have antitumor effect also [24].

\section{Discussion}

Yasargil M et al. [11] analyzed all 114 cases of FM meningiomas surgical treatment, described in the literature from 1924 to 1976 and have set an average level of surgical mortality as 13\%. By now, the largest groups of patients were represented by George B, Lot G [25] - a cooperative study of 143 craniocervical meningiomas in 21 clinics and $\mathrm{Wu} \mathrm{Z}$ et al. [26] - analysis of 114 observations for over 15 years from one clinic (Beijing Tiantan Hospital). Bruneau M., George B. (2008) [9] provided a detailed review of 343 FM meningiomas cases described in English literature from 1987 to 2006, including 40 of their own observations. Pamir MN, Özduman $\mathrm{K}$ [27] in their review provided information on 467 surgically treated FM meningiomas, including 22 of their own observations, in the period from 1978 to 2006 (microsurgical period) and published information on three new own cases. Bruneau M, George $B$ [8] described 57 new cases in addition to the 40 presented earlier in their publication. In addition, a number of articles have been published in recent years, in which 212 new cases of surgically treated FM meningiomas were presented [3,28,31-36]. Thus, about 750 cases of surgically treated FM meningiomas were presented in the accessible literature by 2016 .

In the 1980s and 1990s publications, postoperative mortality was $0 \%$ [37], but in other reports it was $7.5 \%$ - George B et al. [38], Sen CN \& Sekhar LN [39] - 20\%, Kratimenos GP, Crockard HA [4] - 29\%, Crockard HA, Sen CN [40] - 66\%. Recent years studies show a decrease in postoperative mortality to $0-3.6 \%[27,28]$. Bruneau M, George B [9] reported in their review that, before 2008, postoperative mortality ranged from 0 to $25 \%$ (mean $6.2 \%$ ), and higher than $10 \%$ was, mainly, in small groups [41-46]. In 20042015 works postoperative mortality in groups of 11 to 30 patients was from $0 \%[3,43,47]$ to $4.5-6.7 \%[36,44]$. According to the largest analysis, by Wu Z et al. [26], which totals 114 observations - postoperative mortality was $1.8 \%$. Our experience in diagnosing symptomatic FM meningiomas allows us to conclude that these neoplasms have a very specific clinical picture, and their most characteristic manifestations are typical pains in the cervicooccipital area, pyramidal disorders and lower cranial nerves and C1-C2 rootlets dysfunctions. The variability of the clinical symptomatology pointed out by neurologists of previous years [28], is not characteristic of these tumors. The FM meningiomas localization is perhaps the most important characteristic of these neoplasms, providing planning for the forthcoming surgical intervention. Traditionally, FM meningiomas are regarded as anterior, if their matrix is located ventrally on either side of the 
midline; lateral, if the matrix is located between the middle line and the dentate ligament; posterior, if the matrix is located posteriorly from the dentate ligament. Most meningiomas have anterolateral location (68-98\%), less often they are localized in the posterolateral regions, even more rarely in the posterior ones. In most studies, anterolateral and anterior meningiomas are grouped together and considered as anterior or ventral [48-51].

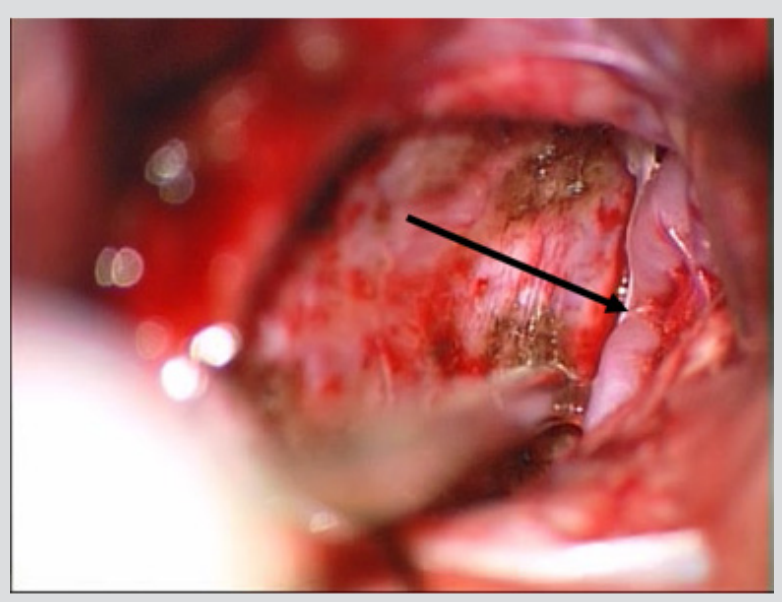

Figure 4: The state after resection of foramen magnum meningioma of anterolateral localization. Pieces of coagulated dura mater, brain stem and merge of vertebral arteries (arrow) with branching left anterior spinal artery can be found.

In our opinion, it is also necessary to mark their lateralization, for a more complete characterization of ventral meningiomas. We mean that the absolute majority of ventral FM meningiomas are lateralized, which determine the side of surgical approach (Figure 2). For example, the state after resection of Foramen Magnum meningioma of anterolateral localization (Figure 4). In our study, tumors of ventral location were lateralized in 31 (91.2\%) observations and only in 1 (2.9\%) case - ventral FM meningioma had no lateralization. Since surgical interventions for such neoplasms have their own specific characteristics, we believe that it is more appropriate to concentrate on the notion of a "surgical corridor", rather than on ventral tumor location $[2,9,13,25]$.

FM meningiomas are limited tumors that spread within the anatomical area without significant bone invasion, the removal of which usually does not require modified surgical approaches. Mainly ventral neoplasms location suggests the use of anterior transoral approaches. However, they proved to be ineffective due to significant drawbacks: increased risk of CSF fistula and infectious complications, poor access to laterally extending tumors resulting in incomplete resection, the risk of postoperative craniocervical instability and soft palate paralysis $[12,26]$. Currently surgical approaches are used for FM meningiomas resection, in accordance to the need of lateral surgical corridor extension: midline posterior, posterolateral transcondylar and ultra-lateral transcondylar. The most optimal for posterior FM meningiomas resection (posterior to the dentate ligament and medial to the vertebral artery) is the midline posterior approach $[2,9]$.
The surgery is performed in patient's "sitting" position (preferable position, to reduce venous bleeding) or "on the side" with rigid head fixation. The risk of venous air embolism is easily solved by anesthetic measures. Skull trepanation (usually resection) is performed in the lower part of the occipital bone with partial resection of C1 posterior arch. Dura mater is incised T- or Y-shaped, retracted with stitches. Goel A et al. [34] believe that even ventral FM meningiomas can be removed using this approach. With posterolateral access, there is a risk of vertebral artery damage at the condylotomy stage, or stricture formation due to excessive coagulation. Expanding the approach to the jugular tubercle is dangerous due to a high risk of lower cranial nerves damage $[2,7,9,13,16,27,32,33,35,49]$.

It is believed that anterolateral (extreme-lateral) access (anterolateral approach or extreme-lateral approach) is indicated by the extradural extension of ventral and ventrolateral FM meningiomas. It was first described by Sen CN, Sekhar LN [39], modified by Salas E et al. [49] and Rhoton AL Jr [32]. It is fundamentally different from posterolateral suboccipital transcondylar approach by pathway. The patient head is laid with a turn of up to $60^{\circ}$. The skin incision is performed behind the mastoid process with the transition to the neck. The occipital bone, C1 posterior arch and lateral mass are allocated. The vertebral artery is mobilized up to the transverse process of $\mathrm{C} 1$, and then the transverse process is resected to the arterial canal. The venous bleeding is easily stopped by coagulation and the use of Surgical. The small branches of V3 segment are coagulated and intersected.

This ensures a safe resection of atlanto-occipital joint and the jugular tubercle. Often, the periosteum around the vertebral artery is calcified and requires careful manipulation. Retrosigmoid craniotomy is performed down to FM and the sigmoid sinus is exposed to the jugular vein bulb. If necessary, the VA transposition [47] is performed, especially with extradural meningioma expansion. C1 and C2 laminectomy is performed to the lower pole of the tumor. After this, the extradural component and the altered bone structures of FM anterior part can be removed. Tumor invasion in this case indicates the volume of bone resection to ensure maximum tumor resection. Then the dura mater is incised, and tumor resection begins $[2,3,5,7,13,17,27,3$ s8,49].

The use of intraoperative neurophysiological monitoring of somatosensory evoked potentials, short latency auditory evoked potentials and electroneuromyography of lower cranial nerves by recording through the intubation tube $(\mathrm{CN} \mathrm{X})$ and with the needle in the sternocleidomastoid muscle (CN XI) and the tongue (CN XII), is considered appropriate $[9,13]$. Bassiouni $\mathrm{H}$ et al. [41], all surgical approaches are divided into two types-retrocondylar, when the articular processes are not resected, and transcondylar, when condyle resection of any volume is performed. In recent years, advantages and disadvantages of these methods have been critically evaluated, and many specialists have begun to use less laborintensive posterior suboccipital access to remove ventrolateral and even ventral FM meningiomas [34]. 
The level of transitory postoperative complications ranges from $39.3 \%$, permanent - from $7.1 \%$. Usually these are lower cranial nerves dysfunctions and ischemic problems are associated with the vertebral artery. The surgical medulla oblongata trauma of neuraxis is rare. The sublingual nerve and jugular vein are most often traumatized during occipital condyle resection $[3,36,39,40]$. Conclusion. Suboccipital lateralized approach with laminectomy to the lower tumor pole is enough to provide adequate microsurgical FM meningiomas removal without atlanto-occipital junction resection. Matrix approach should be performed after partial tumor resection without brain stem traction. The use of intraoperative neuromonitoring provides stem functions control at all stages of tumor removal and spinal artery mobilization.

\section{Conflict of Interest}

All listed authors concur with the submission of the manuscript; all authors have approved the final version. The authors have no financial or personal conflicts of interest.

\section{References}

1. Ostrom QT, Gittleman H, Liao P, Rouse C, Chen Y, et al. (2014) CBTRUS Statistical Report: Primary Brain and Central Nervous System Tumors Diagnosed in the United States in 2007-2011. Neuro Oncol 16(Suppl 4): iv1-iv63.

2. Davis FG, Mc Carthy BJ, Berger MS (1999) Centralized databases available for describing primary brain tumor incidence, survival, and treatment: Central Brain Tumor Registry of the United States; Surveillance, Epidemiology, and End Results; and National Cancer Data Base. Neuro Oncol 1(3): 205-211.

3. Kleihues P, Cavenee WK (2000) Pathology and Genetics of the Tumours of the Nervous System. Lyon: IARC Press pp. 314.

4. Kratimenos GP, Crockard HA (1993) The far lateral approach for ventrally placed foramen magnum and upper cervical spine tumors. $\mathrm{Br} \mathrm{J}$ Neurosurg 7(2): 129-140.

5. Pirotte B, David P, Noterman J, Brotchi J (1998) Lower clivus and foramen magnum anterolateral meningiomas: surgical strategy. Neurol. Res 20(7): 577-584.

6. Boulton MR, Cusimano MD (2003) Foramen magnum meningiomas: concepts, classifications, and nuances. Neurosurg Focus 14(6): 10.

7. Rohringer M, Sutherland CR, Louw DF, Sima AA (1989) Incidence and clinicopathological features of meningioma. J Neurosurg 71(5 Pt1): 665672.

8. Bruneau M, George B (2010) Classification system of foramen magnum meningiomas. J Craniovertebr Junction Spine 1(1): 10-17.

9. Bruneau M, George B (2008) Foramen magnum meningiomas: detailed surgical approaches and technical aspects at Lariboisiere Hospital and review of the literature. Neurosurg Rev 31(1): 19-33.

10. Antunes C, Ramos R, Machado MJ, Filipe MA (2019) Giant posterior fossa meningioma: the importance of early diagnosis and challenges concerning treatment. BMJ Case Rep 12(3): 228454.

11. Yasargil MG, Mortara R, Curcic M (1980) Meningiomas of basal posterior cranial fossa. Advances and Technical Standards in Neurosurgery. Springer pp. 3-115.

12. Miller E, Crockard HA (1987) Transoral transclival removal of anteriorly placed meningiomas at the foramen magnum. Neurosurgery 20(6) 966968.

13. Koos W, Mutula C, Lang J (2002) Color Atlas of Microneurosurgery Thieme-Stuttgart-New York, USA, pp. 652.
14. Babu RP, Sekhar LN, Wright DC (1994) Extreme lateral transcondylar approach: technical improvements and lessons learned. J Neurosurg 81: 49-59.

15. Heros RC (1982) Arteriovenous malformations of the medial temporal lobe. Surgical approach and neuroradiological characterization. J Neurosurg 56(1):44-52.

16. Perneczky A (1986) The posterolateral approach to the foramen magnum: in Surgery in and around the brain stem and the third ventricle. Springer pp. 460-466.

17. Nanda A, Bir SC, Maiti TK, Konar SK, Missios S, et al. (2017) Relevance of Simpson grading system and recurrence-free survival after surgery for World Health Organization Grade I meningioma. Neurosurg 126(1): 201-211.

18. Shanko Y, Navitskaya V, Zamaro A, Zafranskaya M, Krivenko S, et al. (2018) Somatotopic principle of perineural implantation of stem cells in patients with brain injuries. J Neurol Stroke 8(5): 259-261.

19. Kulchitsky V, Zamaro A, Shanko Y, Koulchitsky S (2018) Positive and negative aspects of cell technologies in cerebral diseases. J Neurol Stroke 8(2): 87-88.

20. Kulchitsky V, Zamaro A, Shanko Y, Koulchitsky S (2018) Prospects of Perineural Implantation of Stem Cells in Recovery of Neural Networks' Functions in Brain Diseases. Biomed J Sci\&Tech Res 10(3): 1-4.

21. Shanko Y, Navitskaya V, Zamaro A, Krivenko S, Zafranskaya M, et al. (2018) Prospects of Perineural Administration of Autologous Mesenchymal Stem Cells of Adipose Tissue in Patients with Cerebral Infarction. Biomed J Sci\&Tech Res 10(1) 1-3.

22. Deierborg T, Roybon L, Inacio AR, Pesic J, Brundin P (2010) Brain injury activates microglia that induce neural stem cell proliferation ex vivo and promote differentiation of neurosphere-derived cells into neurons and oligodendrocytes. Neuroscience 171(4): 1386-1396.

23. Tornero D, Tsupykov O, Granmo M, Rodriguez C, Grønning Hansen M, et al. (2017) Synaptic inputs from stroke-injured brain to grafted human stem cell-derived neurons activated by sensory stimuli. Brain 140(3): 692-706.

24. Zamaro A, Zhukava T, Kulchitsky V (2018) Antitumor effects of allogenic mesenchymal stem cells. Arch Cancer Res 6: 34.

25. George B, Lot G (1995) Anterolateral and posterolateral approaches to the foramen magnum: technical description and experience from 97 cases. Skull Base Surg 5(1): 9-19.

26. Wu Z, Hao S, Zhang J, Zhang L, Jia G (2009) Foramen magnum meningiomas: experiences in 114 patients at a single institute over 15 years. Surg Neurol 72(4): 376-382.

27. Pamir MN, Özduman K (2015) Foramen Magnum Meningiomas. Clinical Gate.

28. Shanko Y, Smeyanovich A, Bulgak V, Rodzich A (2015) Intraoperative monitoring of foramen occipitalis magnum meningiomas surgery significantly improves the preservation of neurological functions. Act Nerv Super Rediviva 57(3): 72-76.

29. Kano T, Kawase T, Horiguchi T, Yoshida K (2010) Meningiomas of the ventral foramen magnum and lower clivus: factors influencing surgical morbidity, the extent of tumour resection, and tumour recurrence. Acta Neurochir (Wien) 152(1): 79-86.

30. Roberti F, Sekhar LN, Kalavakonda C, Wright DC (2001) Posterior fossa meningiomas: surgical experience in 161 cases. Surg Neurol 56 (1): 8-20.

31. Spektor S, Anderson GJ, McMenomey So, Horgan MA, Kellogg JX, et al. (2000) Quantitative description of the far-lateral transcondylar transtubercular approach to the foramen magnum and clivus. J Neurosurg 92(5): 824-831.

32. Rhoton ALJr (2000) The far-lateral approach and its transcondylar, supracondylar and paracondylar extensions. Neurosurgery 47(3): 195209. 
33. Sohn S, Chung CK (2013) Conventional Posterior Approach without Far Lateral Approach for Ventral Foramen Magnum Meningiomas. J Korean Neurosurg Soc 54(5): 373-378.

34. Goel A, Desai K, Muzumdar D (2001) Surgery on anterior foramen magnum meningiomas using a conventional posterior suboccipital approach: a report on an experience with 17 cases. Neurosurgery $49(1)$ 102-106.

35. Marin Sanabria EA, Ehara K, Tamaki N (2002) Surgical experience with skull base approaches for foramen magnum meningioma. Neurol Med Chir 42(11): 472-478.

36. Borba LA, de Oliveira JG, Giudicissi Filho M, Colli BO (2009) Surgical management of foramen magnum meningiomas. Neurosurg Rev 32(1) 49-58.

37. Bertalanffy H, Gilsbach JM, Mayfrank L, Klein HM, Kawase T, et al (1996) Microsurgical management of ventral and ventrolateral foramen magnum meningiomas. Acta Neurochir Suppl 65: 82-85.

38. George B, Lot G, Boissonnet H (1997) Meningioma of the foramen magnum: a series of 40 cases. Surg Neurol 47(4): 371-379.

39. Sen CN, Sekhar LN (1990) An extreme lateral approach to intradural lesions of the cervical spine and foramen magnum. Neurosurgery 27(2): 197-204.

40. Crockard HA, Sen CN (1991) The transoral approach for the management of intradural lesions at the craniovertebral junction: review of 7 cases. Neurosurg 28(1): 88-97.

41. Bassiouni H, Ntoukas V, Asgari S, Sandalcioglu EI, Stolke D, et al. (2006) Foramen magnum meningiomas: clinical outcome after microsurgical resection via a posterolateral suboccipital retrocondylar approach. Neurosurg 59(6): 1177-1185.

42. Kandenwein JA, Richter HP, Antoniadis G (2009) Foramen magnum meningiomas -experience with the posterior suboccipital approach. $\mathrm{Br}$ Neurosurg 23(1): 33-39.

\section{ISSN: 2574-1241}

DOI: 10.26717/BJSTR.2019.18.003081

Kulchitsky Vladimir. Biomed J Sci \& Tech Res

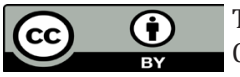

This work is licensed under Creative Commons Attribution 4.0 License

Submission Link: https://biomedres.us/submit-manuscript.php
43. Giussani C, Guida L, Canonico F, Sganzerla EP (2018) Cerebral and occipito-atlanto-axial involvement in mucopolysaccharidosis patients: clinical, radiological, and neurosurgical features. Ital J Pediatr 44(Suppl 2): 119.

44. Zenonos G, Kondziolka D, Flickinger JC, Gardner P, Lunsford LD (2012) Gamma Knife surgery in the treatment paradigm for foramen magnum meningiomas. J Neurosurg 117(5): 864-873.

45. Talacchi A, Biroli A, Soda C, Masotto B, Bricolo A (2012) Surgical management of ventral and ventrolateral foramen magnum meningiomas: report on a 64-case series and review of the literature. Neurosurg Rev 35(3): 359-367.

46. Bydon M, Ma TM, Xu R, Weingart J, Olivi A, et al. (2014) Surgical outcomes of craniocervial junction meningiomas: A series of 22 consecutive patients. Clin Neurol Neurosurg 117: 71-79.

47. Ma XJ, Zhang GJ, Wang W, Li D, Wu Z, et al. (2019) Proposed Treatment for Intracranial Transitional Meningioma: a single-center series of 298 cases. World Neurosurg pii: S1878-8750(19) 30772-7.

48. Sharma BS, Gupta SK, Khosla VK, Mathuriya SN, Khandelwal N, et al. (1999) Midline and far lateral approaches to foramen magnum lesions. Neurol India 47(4): 268-271.

49. Salas E, Sekhar LN, Ziyal IM, Caputy AJ, Wright DC (1999) Variations of the extreme-lateral craniocervical approach: anatomical study and clinical analysis of 69 patients. J Neurosurg 90(2 Suppl): 206-219.

50. Stein BM, Leeds NE, Taveras JM, Pool JL (1963) Meningiomas of the foramen magnum. J Neurosurg 20: 740-751.

51. Arnautovic KI, Al-Mefty O, Husain M (2000) Ventral foramen magnum meningiomas. J Neurosurg 92(1 Suppl): 71-80.

\begin{tabular}{ll}
\hline $\begin{array}{l}\text { BIOMEDICAL } \\
\text { RESEARCHES }\end{array}$ & Assets of Publishing with us \\
\hline & - Global archiving of articles \\
\hline & - Immediate, unrestricted online access \\
\hline
\end{tabular}

